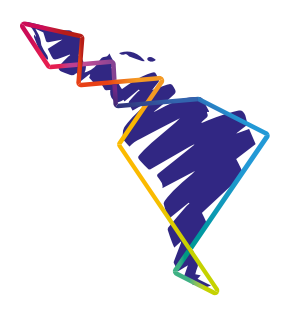

\title{
El feminismo de cara al acceso a la justicia para las mujeres
}

\section{Feminism in view of access to justice for women}

\section{Feminismo diante do acesso à justiça para as mulheres}

\author{
Verónica Ethel Rocha Martínez
}

\begin{abstract}
Resumen
El presente es un análisis que profundiza y narra las circunstancias de vida de las mujeres al demandar justicia ante las instancias que la administran. Muestra desde el aporte documental, hemerográfico y testimonial, el contexto de impunidad y de transgresión ante la denuncia de delitos de género. Explica los esfuerzos y surgimiento de los colectivos feministas en aras de aportar apoyo jurídico y emocional a las víctimas, pero, también, es un documento que propone fortalecer la capacidad para reinterpretar, construir y fundamentar la identidad de género en parámetros ajenos a la objetivación y el maltrato.
\end{abstract}

Palabras clave: Acciones afirmativas, feminismo, equidad, justicia, perspectiva de género, vida libre de violencia para las mujeres.

\begin{abstract}
The present exposition is an analysis that deepens and narrates the circumstances of life of women when they demand justice before the administrating authorities. It shows from the documentary, hemerographic and testimonial contribution, the context of impunity and transgression upon

Recibido: 12-3-2021 - Aceptado: 13-5-2021

1 La autora es maestra en Gestión de Instituciones Educativas con modalidad virtual, egresada de la Universidad Autónoma del Estado de Hidalgo, especialista en Entornos Virtuales de Aprendizaje acreditada por Virtual Educa y la Organización de Estados Iberoamericanos y Licenciada en Pedagogía por la Universidad Nacional Autónoma de México. Ha realizado estudios sobre ciberacoso, Libertades sociales y derechos individuales, Curadurías emergentes, Escritura de proyectos culturales, entre otros. Colabora en diferentes revistas digitales en temáticas de género, jurídicas, de promoción lectora y acerca de políticas educativas; ha escrito reseñas, cuentos y poemas. Es titular del Colectivo Tlahtolli Ollin, Palabra en movimiento organización dedicada a la promoción lectora y cultural en el Estado de México. Correo electrónico: palabraenmovimiento2018@ gmail.com, (D) https://orcid.org/0000.0003-0857-1476
\end{abstract}


the denunciation of gender crimes. It explains the efforts and emergence of feminist groups in order to provide legal and emotional support to victims, but it is also a document that proposes to strengthen the capacity to reinterpret, build and base gender identity on parameters other than objectification and abuse.

Keywords: Affirmative actions; Feminism; Equity; Justice; Gender perspective; Life free of violence for women.

\section{Resumo}

O presente é uma análise que aprofunda e narra as circunstâncias de vida das mulheres quando reclamam justiça perante as autoridades que a administram. Mostra, a partir da contribuição documental, hemerográfica e testemunhal, o contexto de impunidade e transgressão diante da denúncia de crimes de gênero. Explica os esforços e o surgimento de grupos feministas para dar apoio legal e emocional às vítimas, mas também é um documento que se propõe a fortalecer a capacidade de reinterpretar, construir e basear a identidade de gênero em parâmetros outros que a objetificação e o abuso.

Palavras-chave: Ações afirmativas; Feminismo; Equidade; Justiça; Perspectiva de gênero; Vida sem violência para mulheres.

\section{Introducción}

El presente análisis describe el surgimiento de diferentes colectivos y grupos feministas ante un contexto de transgresión y desigualdad que escinde el acceso a derechos básicos de muchas mujeres en México que demandan acceso a la justicia.

Es un esfuerzo por documentar, a partir de aportes hemerográficos, informes, políticas públicas y testimonios, las experiencias, posturas y transgresiones de las mujeres ante la impunidad y la corrupción en zonas en las que existe alerta de género $y$, por tanto, son de alto riesgo para ellas.

El objetivo de este ensayo es aportar una mirada de acompañamiento para recuperar recursos jurídicos, vivencias y posibles soluciones a las difíciles situaciones que enfrentan las mujeres cuando luchan por sus derechos y por respuesta obtienen la falta de equidad y acceso a ellos, cuando, en la mente de sus atacantes, rompen un pacto de silencio misógino impuesto ante un contexto de impunidad y transgresión.

Se pretende mostrar caminos viables para la convivencia entre hombres y mujeres en aras de lograr el respeto necesario para experimentar vidas libres de maltrato. 
Finalmente, se aportan algunas reflexiones finales para cambiar el acontecer en la relación entre hombres y mujeres en aras de desempoderar nuestras interacciones.

\section{Idea feminista}

El feminismo se abre camino en un mundo globalizado como una postura política indispensable en la agenda de cualquier país; actualmente proliferan las vertientes de esta inclinación. Cabe aclarar, cuán frecuente es encontrar declaraciones, en apariencia feministas, emitidas por figuras públicas cuya única finalidad es sumar votos o lograr la simpatía política.

La lucha feminista abarca décadas de acciones entre marchas, publicaciones, foros, talleres, encuentros, colectivos, asociaciones, pero, sobre todo, explica Graciela Hierro (2002) se llega al feminismo al recuperar la propia historia, ante la conciencia de las vivencias de dolor y sufrimiento que nos suceden por el solo hecho de ser mujeres. El feminismo es, entonces, una actitud de compromiso y transformación de las mujeres; en ese sentido, no se requiere acreditar a quienes, sin manifestarse, han asumido esta vía de encuentro desde hace tiempo, sin proclamarlo.

Los caminos para reconocer los trayectos feministas viajan por diversidad de inquietudes, la única característica común es propiciar posturas reflexivas, críticas y de transformación ante las desigualdades e injusticias, sustentadas y promovidas desde culturas en extremo machistas y misóginas.

¿Qué significa esto? implica horadar la historia cotidiana, en la vida de las mujeres, para encontrar ahí, múltiples heridas. Porque, siendo honestas, ninguna podría decir que no enfrentó en algún momento y lugar el discurso de supremacía de los hombres, como un obstáculo infranqueable o un evento desafiante ante circunstancias insólitas -incluso solicitando obediencia ciega- en el afán de perpetuar la cultura imperante en las instituciones -llámense estas familia, escuela, iglesia, partido o Estado-.

Actualmente los feminismos se abren, constituyen y constriñen entre sí, ante ideas excluyentes y diversas, estas abarcan desde la búsqueda de otro modo de ser mujer -ruta de indagación en Rosario Castellanos con el poema "Meditaciones en el umbral" (Citado en Hierro, 2000)- hasta las aristas más radicales, capaces de proclamar un separatismo, incapaz de considerar la participación masculina en su acontecer.

Si se busca una transformación duradera y consistente en la relación entre hombres y mujeres, el fundamento deberá ser la justicia y el respeto y, tal cambio no puede suceder en un clima de violencia y de exclusión. 
La necesidad de ver, oír y sentir lo que las mujeres viven debe ser parte de esa transformación, en tanto visualice aquello que la misoginia sustenta y proclama. En consecuencia, lo que el ser hombre significa es, a la par, un cuestionamiento igual de importante en la lucha feminista.

Sin embargo, al trastocar identidades, que de una u otra forma justifican el sometiendo de las mujeres y la supremacía de los hombres, es preciso convocar a hombres y mujeres en el afán de reconocer su capacidad para reinterpretar, construir y fundamentar su identidad de género, en parámetros ajenos a la objetivación y el maltrato.

Tal posibilidad de reconocimiento pleno debe interpelar, en sí mismo, el daño causado en circunstancias de maltrato entre hombres y entre mujeres.

En relación con aquello que compete al Estado, un gobierno respetuoso y apegado a los derechos humanos se ejerce cuando no se omite la responsabilidad adquirida, en tanto sea posible vigilar, mejorar, salvaguardar los mecanismos de procuración de justicia a favor de las mujeres en entornos respetuosos, eficientes y eficaces, a fin de restituir el Estado de derecho.

La garantía de apego a los derechos humanos y de respeto hacia las mujeres también debe prevalecer cuando en el afán de lograr una justicia plena, quien denuncia el silencio, la omisión y el solapamiento contraviene la postura de un Estado incapaz de generar condiciones para ejercer los derechos inherentes a una vida plena.

Las acciones afirmativas, igual que la perspectiva de género, son posicionamientos actuales ante el abordaje de las problemáticas femeninas, con miras a garantizar esos espacios de vida libres de violencia, si bien, estos términos se proclaman cada vez con más frecuencia en el lenguaje político y son ideas producto de reflexiones y disertaciones valiosas; en los hechos, no pueden avanzar, pues encuentran graves obstáculos al colisionar con culturas cuya raíz se sustenta en un machismo misógino instaurado en las prácticas institucionales, en culturas ocultas de sometimiento, que existen y no se cuestionan.

Por ende, no basta visualizar el maltrato y la violencia hacia las mujeres tanto en la vida privada como en los espacios públicos, faltan instrumentos jurídicos realmente eficaces de protección y de restitución de derechos, y, con ellos, cambios significativos y empáticos en las actitudes de los hombres y de las mujeres inmersos en la procuración de la justicia.

En ese sentido, será la participación consciente, responsable y comprometida de la sociedad en su conjunto, la que abra posibilidades reales a las acciones afirmativas, 
en tanto sean un ejercicio cotidiano en todo espacio de relación con las mujeres, determinado por el poder.

Si bien, reconocer las diferentes formas de violencia hacia las mujeres es el primer eslabón para desarticular la impunidad imperante en todos los ámbitos de la sociedad, -incluidas las culturas laborales e institucionales y la violencia ejercida en la vida social y privada- también se deben cuestionar las formas desde dónde se asume y se articula la transgresión a sus derechos.

Puesto que, en acciones como la omisión, el solapamiento, el discurso de odio se observa el sustento discursivo y mediático para generar los actos más atroces en detrimento de las mujeres. Llegamos a un punto medular, en tanto posicionar un cambio realmente consistente implica revisar las prácticas que promueven y reproducen la cultura misógina entre hombres y mujeres en todos los espacios de la vida en común.

Sin duda, es una labor inconmensurable que atañe a los aspectos formativos del ser humano, dado que esas prácticas tan arraigadas no cambiarán si no se cuestionan, critican, sancionan y desarticulan. Entonces resulta indispensable criticar, exhibir, recrear, movilizar toda acción posible para lograr esos cambios culturales de fondo, para que su fundamento no sea el sometimiento del más vulnerable.

En ese contexto, cabe aclara que las buenas intenciones, así como los buenos discursos no restituyen derechos, no reparan la destrucción cometida a una persona ante violaciones sistemáticas a sus derechos, no traen a la vida a las niñas y mujeres desaparecidas, y ante las cifras de violencia contra las mujeres, de nada sirven, si los casos de feminicidio aumentan -en países como México y de acuerdo a las cifras publicadas por el Secretariado Ejecutivo del Sistema Nacional de Seguridad Pública (SESNP, 2020), las víctimas de feminicidio de enero a noviembre del 2020 correspondieron a 860 , las víctimas mujeres de homicidio doloso en ese mismo período en el nivel nacional ascendieron a 2567, fueron 2838 mujeres las que sufrieron homicidio culposo y 52944 las víctimas femeninas de lesiones dolosas. Destacó el Estado de México con 12762 casos y el Estado de Aguascalientes debido a que ahí, no se distingue el sexo de las víctimas de lesiones dolosas y se registran en la categoría de sexo "No identificado" - . Las cifras exhiben una realidad angustiante acerca de la situación que viven las mujeres en México.

En el informe revisado, también destaca la clasificación de los delitos que afectan cotidianamente a las mujeres, estos son: violencia contra la mujer, abuso sexual, acoso u hostigamiento sexual, violación, violencia de pareja y violencia familiar (SESNSP, 2020). 
De manera introductoria el documento revisado explica que toda denuncia penal sigue un procedimiento. El primer paso corresponde a la apertura de la carpeta de investigación, después se procede a establecer el tipo penal a partir de describir el hecho delictivo y al avanzar la investigación, ese hecho inicial puede ser reclasificado e incluso se puede determinar la no existencia del delito (SESNSP, 202).

Se observa en el funcionamiento del Sistema de administración de justicia un sesgo importante cuando quien denuncia es una mujer, más aún, si se trata de delitos tipificados como ciberacoso o feminicidio. De manera progresiva quien denuncia se sentirá vulnerable ante un sistema judicial habitado mayoritariamente por hombres, en algún punto del proceso el agente del Ministerio Público podrá indicar a la denunciante el riesgo de ser ella la inculpada.

En esa advertencia, emitida por un funcionario público, cuya función es orientar a la víctima en todo momento, se instaura una práctica que la amedrenta y la disuade, gradualmente a desistir en la denuncia. El recurso resulta muy efectivo para un sistema que solapa y encubre al infractor, pues el delito en muchos casos no llega a formularse.

Otras situaciones similares ocurren cuando las investigaciones no avanzan o los delitos se reclasifican y, finalmente, la carpeta de investigación se archiva por falta de pruebas.

Las mujeres en México, con frecuencia se convierten en sus propios agentes de investigación, a fin de aportar indicios para probar su dicho, es por eso que han surgido colectivos de mujeres cuya misión ha sido orientar a quien denuncia para salvaguardar su integridad.

En Ciudad Juárez, por ejemplo, ante el hallazgo de 8 cuerpos de mujeres asesinadas en una zona conocida como Campo algodonero en 2001, la Red de mujeres de Ciudad Juárez brindó apoyo a las demandantes e interpuso contra el Estado Mexicano, ante la Comisión Interamericana de Derechos Humanos, una demanda. Se determinó que dichos asesinatos se inscribían en un contexto de violencia e impunidad, y en la sentencia emitida por el organismo internacional, se reconoció la violencia de género en ese municipio y se obligó al Estado Mexicano a generar mecanismos de vigilancia e investigación con perspectiva de género (Hincapié, 2017; Corte Interamericana de Derechos Humanos, 2009).

Para las mujeres mexicanas el acceso a la justicia representa un suplicio, es clara la semejanza con lo expuesto por Foucault en 1976 (2015) al referirse a la infracción 
y su pena como un ritual político. El filósofo argumenta que la ceremonia de penalización del delito forma parte de las manifestaciones del poder, pues quien infringe la ley, "también lesiona a quien gobierna porque injuria con ello la dignidad de su carácter" (Foucault, 2015).

Cabe preguntar, de qué son culpables las mujeres al denunciar una violación a sus derechos, es obvio que ninguna, estrictamente hablando, pero en la cultura del poder misógino esa transgresión se encuentra en la exigencia, al demandar a quien gobierna que reconozca sus derechos como mujer.

Este ensayo es un llamado a los hombres y mujeres del planeta para que en un acto de conciencia puedan distinguir, en el ejercicio de sus profesiones y vidas, cuando se vulnera el derecho de las mujeres a existir y expresar lo que han tenido que sufrir en su lucha por acceder a la justicia. También, pretende posicionar a las personas para asumir, en cada aspecto de su vida, el férreo compromiso de propiciar acciones afirmativas de inclusión, respeto, tolerancia y empatía entre hombres y mujeres.

\section{Ser mujer}

Las manifestaciones de mujeres a favor de sus derechos han sido recurrentes en la segunda década del siglo XXI. En México, el 24 de abril de 2016 las marchas femeninas en cinco ciudades denunciaron la falta de acciones efectivas por parte del Estado para defender su vida y su integridad. Posteriormente, en 2017 cientos de ellas en diferentes partes del mundo exigieron, el Día Internacional de la Mujer, la eliminación de la discriminación, la violencia y las desigualdades de género (Hincapié, 2017).

En la misma fecha, pero en 2019, la lucha femenina logró una victoria sin precedentes al convocar de manera global marchas a favor de sus derechos y en repudio de toda violencia hacia su persona (BBC, 2019). En ese sentido, el noticiero BBC (2019) estimó en millones el número de mujeres que se reunieron y destacó el avance del movimiento feminista en América Latina. Las cifras mostraron, como en la punta de un iceberg, el enojo de las mujeres ante el hostigamiento y acoso sexual que viven en los espacios públicos y privados.

Un referente importante corresponde a las acciones llevadas a cabo en la Ciudad de México, a partir de 2019, por el gobierno de Claudia Sheimbaum ante la emisión de la declaratoria de alerta por violencia contra las mujeres, la declaratoria contempla 11 medidas para garantizar a niñas, jóvenes y mujeres una vida libre de violencia en la entidad (Gobierno de la Ciudad de México, 2019). 
Destacan las medidas de capacitación dirigidas a quienes son administradores de justicia en sus diferentes niveles, el auditar los procesos en materia de justicia para las mujeres y el crear unidades de atención especializadas en delitos contra la mujer² (Gobierno de la Ciudad de México, 2019).

La medida más urgente correspondió a la creación de la estrategia "Viaja segura" que incluyó la creación de Módulos en tres estaciones del Sistema de Transporte Colectivo Metro, con abogadas capacitadas para brindar apoyo, asesoría y atención ante este tipo de denuncias (Secretaría de las mujeres, 2021).

Además, se iniciaron una serie de campañas informativas en los medios de transporte urbano para ejemplificar las diversas formas en que la violencia opera contra las mujeres y la frecuencia de esas transgresiones. A las usuarias del transporte colectivo, les quedó claro el riesgo latente que se vive, cotidianamente, al viajar en cualquier vehículo colectivo.

Sin embargo, ese escenario no era nuevo en 2019, ya que la encuesta realizada en 15 ciudades del mundo, acerca de la seguridad del transporte público, en 2014, por la Thomson Reuters Foundation mostró, en cifras, la magnitud del problema en los sistemas de transporte colectivo, ya que de cada 10 mujeres encuestadas, según señala Boros, en 2014:

\section{- 8 enfrentaron miradas morbosas \\ - 6 habían vivido manoseos y arrimones}

Las cifras impactan y resultaron datos de interés para los proyectos sobre transporte y equidad de género emitidos por el Banco Interamericano de Desarrollo, organismo evaluador del Sistema de movilidad de la Ciudad de México, que lo declaró como el más riesgosos para las mujeres en América Latina y el Caribe (BID, 2016).

Cabe agregar, las estimaciones de la Thomson Reuters Foundation se utilizaron también en la campaña "Viaja segura", en calcomanías visibles al interior de los vagones del Metro. ¿Por qué algo tan común y cotidiano tendría que afectar la integridad de las mujeres?

Si bien, hay mujeres que han logrado defenderse, denunciar, parar al agresor, sacarlo de los vagones confinados, también son muchas las mujeres que se paralizan

2 Dos medidas enunciadas en la declaratoria de alerta por violencia contra las mujeres en la Ciudad de México que atañen a la administración de justicia son:

- Certificar a ministerios públicos, asesores jurídicos y peritos en la atención de mujeres víctimas de violencia.

- Impartir una formación integral que aborde la perspectiva de género y los derechos humanos a los cuerpos policiales. 
y simplemente no saben cómo ejercer sus derechos, porque se ven vulneradas de forma cotidiana en múltiples contextos.

Recuperar y fortalecer "el ser persona" en un mundo en donde la misoginia impera como cultura dominante, implica restituir un poder perdido en el silencio, para defender la integridad y la valía. No es tan fácil recuperar la autoestima en sesiones de apoyo psicológico, si más tarde, la burla y el ultraje persisten. De qué sirve la autoestima forjada a pulso, cuando se llega a la cueva del lobo en donde se vive la humillación.

¿Quiénes deberían trabajar su autoestima, las víctimas o los agresores, las denunciantes o los apoderados de justicia que les niegan el acceso a las carpetas de investigación, por ser mujeres, estar solas, no tener recursos suficientes y, con todo esto en su contra, atreverse a denunciar a hombres iguales a ellos?

Defenderse de una agresión sexual no es algo que se aprenda en las calles, se logra, cuando existe respeto y aprecio a lo largo de las experiencias más significativas de la vida, a partir de saber a cabalidad que el ser mujer no es un error.

Es este el esbozo de una cultura que enseña a compartir responsabilidades a la par, sin importar los roles aprendidos. Es cierto, apreciar el ser mujer, es un privilegio que se logra, en definitiva, día con día, ante el espejo de tu realidad, forjada al descubrir lo valiosa que eres por ser tú misma, sin importar cuánto dinero tengas o los títulos acumulados.

Ser persona, implica reconocer la vida maravillosa y singular en cada existencia extraordinaria y cotidiana. Es, a la vez, un lazo de empatía ante trayectos diversos, construidos colectivamente en la autonomía y la autorrealización; se trata entonces, de vencer el miedo y afrontar una y otra vez, por los cauces de la legalidad, el que los delitos como el ciberacoso, el hostigamiento y el acoso sexual, la violencia intrafamiliar, el feminicidio e incluso el moobing laboral se miren, se sancionen y se aborden desde diferentes vías.

Ser mujer, no debería implicar cuidarte día y noche del maltrato de hombres y mujeres, para quienes la vida que torturan no vale nada. Incluso cuando desde una misoginia maquillada de feminismo, hacer sufrir y pagar culpas fabricadas a otras mujeres, es una práctica para desarticular a quien pretende denunciar el discurso de odio fabricado por el poder que se ríe a carcajadas.

Lo cierto es que estos sucesos tan irreales, son similares a escindir el mundo en "buenos y malos", pero quién en su sano juicio sería "bueno" al ultrajar los derechos de otro ser humano. 
Los que se creen "buenos" lastiman, agreden, humillan, roban, desacreditan, torturan, vigilan, inculpan a mujeres que han sido capaces de denunciar esa misoginia. Ese es el motivo por el que serán llamadas brujas, malas, anárquicas, irracionales, intuitivas, lesbianas. Paradójicamente, esas mujeres que no han cometido delito alguno, en pleno siglo XXI, son sometidas a vigilancia y castigo.

Si esto ocurre con la anuencia de una sociedad misógina, no nos hemos alejado de las torturas inquisitoriales, aún hoy, el cuerpo de la mujer es vejado y exhibido en redes sociales, expuesto ante todos, tan solo porque esa exhibición morbosa es lucrativa.

Así las cosas, debe quedar claro que ser mujer en este momento, no debe ser vivir con la angustia ante la constante amenaza de sufrir una agresión por un padre, un abuelo, un novio, un chofer, un cobrador de autobús, un maestro, un policía, un colaborador, un médico, un asociado en una tienda departamental, un vecino, una vecina, una maestra, un gerente, una enfermera, un conductor, un joven, un niño, una niña, un locutor, un comentarista, un comediante, un presidente, una alcaldesa, un rector o un familiar.

\section{EI feminismo ante el feminicidio}

El feminismo existe, se muestra y cabalga sobre ideas y acciones, actualmente los grupos más radicales sostienen una postura separatista. Sin embargo, bajo esa idea, posiblemente se termine asfixiando lo fundamental entre hombres y mujeres.

La furia, por otro lado, se expresa de formas diversas, por ejemplo, en manifestaciones de mujeres como la ocurrida el 16 de agosto del 2020 en la Ciudad de México, con la participación de diversos colectivos feministas (Gómez, 2020), quienes en su recorrido hacia el Zócalo capitalino pintaron de rosa los monumentos históricos de una de las avenidas más antiguas; el acto resaltó en diferentes medios de comunicación. Sus historias, por otro lado, no aparecieron impresas o editadas en ningún periódico o noticiero pues nadie les preguntó sobre la lista interminable de agravios y violencia que han vivido a lo largo de sus vidas y el motivo por el cual se sumaban a esa manifestación.

A estos grupos de mujeres se les distingue de otras agrupaciones y se les llama anarquistas, en las diferentes marchas en las que han participado, se han enfrentado a los insultos de hombres a su paso, al bloqueo de las fuerzas policiales, a luchas frontales cuerpo a cuerpo, como amazonas sin territorio.

La transgresión al orden, conlleva ser violentadas incluso por los comandos de contención, como ocurrió el 28 de septiembre del 2020, en la marcha a favor de 
la legalización nacional del aborto cuando una manifestante fue vulnerada por una policía, quien toca bajo su falda, su entrepierna. Este clima de enfrentamientos entre manifestantes y policías, a cargo de la seguridad capitalina, ha llevado a un punto álgido cada encuentro.

Las mujeres vistas desde el aparato legislativo, lograron el voto femenino el 17 de octubre de 1953 (Instituto Nacional para el Federalismo y el Desarrollo Municipal, 2019); la Ley para la igualdad entre hombres y mujeres fue otro avance importante y ocurrió en agosto de 2006, y, posteriormente, se modificó en junio de 2018 (DOF, 2018); además, se promulgó la Ley general de acceso de las mujeres a una vida libre de violencia, documento publicado en 2007 y modificado en enero del 2021 (Marco Normativo de la Comisión Nacional de Derechos Humanos, 2021).

El contexto en el cuál se emite una ley para garantizar a las mujeres una vida libre de violencia nos indica la existencia de un país donde la misoginia imperante impide la equidad entre hombres y mujeres.

En esa Ley, se define la violencia feminicida como la más extrema de las formas de violencia que pueda vivir una mujer. Señala el feminicidio como un producto de la violación a los derechos humanos, en los ámbitos público y privado; describe cómo se articula ante un conjunto de conductas impunes de tipo misógino, toleradas por el Estado y la sociedad con consecuencias fatales para las mujeres (Marco Normativo de la Comisión Nacional de Derechos Humanos, 2021).

Si entendemos el feminicidio en su origen y manifestaciones, ninguna ley tiene utilidad jurídica real al toparse con un sistema de administración de justicia cuya postura misógina encubre, sesga, soslaya, vigila y somete a quien denuncia. Cierto es que, ante la demanda de justicia de las mujeres, el sistema es eficaz y eficiente para encubrir a los infractores.

A los hombres, les queda claro que, si la ley no se cumple a favor de ellas, es porque son ellos mismos, en muchos casos, quienes legislan; y en este país, como en muchos otros, gran parte de la sociedad asume posturas misóginas con plena consciencia de ello y sin inmutarse.

Debemos transitar a un escenario nuevo, en el que los buenos hombres nos expliquen a las mujeres ¿cómo podríamos cambiar la misoginia imperante por un respeto genuino tanto en la administración de justicia como en la consulta médica, en la labor de parto, en la escuela, en la universidad y en todos los espacios en los que se habita a la par con ellos? 
¿Qué duele tanto, por qué resulta tan difícil lograr una palabra de respeto y basta un segundo para la burla? A los hombres les enseñan a asumir el poder desde pequeños en todos los espacios de su vida, a pelear ese dominio, por tanto, la equidad de género y el respeto, no pueden ser territorios conquistados por la fuerza, pues sus trayectos no pretenden dominar o sujetar a nadie.

Si la misoginia persiste y se fortalece, es porque reditúa transgredir los derechos de las mujeres, la trata de personas, con fines de explotación sexual, representa una de las principales fuentes de ingreso del crimen organizado (Hincapié, 2017). En igual circunstancia, el ciberacoso, cuando exhibe los aspectos más íntimos de la vida de las mujeres, es un producto redituable del cual se nutre el aparato mediático a partir de la emisión de mensajes inmersos en las propuestas de entretenimiento, publicidad y mercadotecnia política.

La transgresión a la vida privada de las mujeres ocurre, con frecuencia, en represalia por denunciar un delito, se instaura en la vida pública de un país como venganza articulada desde las redes sociales y apoyada por los medios de comunicación.

La participación en el maltrato a una mujer, derivada de la manipulación mediática, también implica -al menos en mi caso y creo no ser la única- el espionaje con miras a exhibir los aspectos más íntimos de su vida para desarticularla, someterla y desacreditarla moralmente. Es una violación voyerista que se solapa y justifica ante una sociedad inmersa en el maltrato de mujeres, de manera cotidiana, que justifica estas atrocidades inauditas y las convierte en vano entretenimiento.

En este tipo de violencia inédita -mucho más atroz que cualquier otra- el discurso de odio se inscribe como recurso para la agresión; quienes hostigan, utiliza códigos de acoso tomados de la vida de la persona sometida a vigilancia social y, con ellos, le hacen saber que su vida es pública.

Si el Estado participa en estos actos, si articula desde el poder la transgresión a las mujeres que le exigen justicia, si induce a los ciudadanos para castigar sin piedad la insurrección y, desde el descrédito, burla los derechos humanos más esenciales; si se somete a mujeres extraordinariamente valientes y valiosas, qué puede quedar en pie.

\section{Algunas reflexiones finales}

Ser mujer importa, persistir en ello no debería costar ninguna vida. Cuáles serían las actitudes para sostener relaciones humanas sanas, lazos de aprecio, comunidades en donde sea valorado el trabajo femenino, en donde el sometimiento no sea la pauta y la violencia, incluso la mediática no ultraje lo femenino. 
El esfuerzo formativo para liberar las instancias procuradoras de justicia del sesgo misógino requiere replicarse y abarcar a cada organismo público, a los mensajes emitidos en redes sociales y en medios de comunicación masiva hasta llegar a cada hogar.

Son muchas las tareas y retos, inmersos en el afán de liberar del discurso y de los hechos, la transgresión a las mujeres; en gran parte, esta es una tarea para recuperar en las sociedades la empatía, el respeto, la tolerancia y el bloqueo emocional de quienes han vivido en el maltrato toda su vida, de quienes justifican el hostigamiento y la provocación y hacen del mundo un lugar cada día más violento y descontrolado.

La incertidumbre en el acontecer humano no debe aislar a las personas, la agresión parece ser la pauta y el sustento de las relaciones y, en este tipo de comportamiento, suele ganar el más fuerte. Ante este panorama se trata entonces de desempoderar las interacciones entre hombres y mujeres.

\section{Referencias}

Barrales, A. (4 de diciembre, 2020). Violencia de género, inaceptable y evitable. El Universal. Obtenido de: https://www.eluniversal.com.mx/opinion/alejandra-barrales/ violencia-de-genero-inaceptable-y-evitable

BBC News. (2019). Día de la mujer. Millones de mujeres marcharon en todo el mundo en el día de la mujer para repudiar la violencia y pedir por la igualdad de género. $\mathrm{BC}$ News Mundo. Obtenido de: https://www.bbc.com/mundo/noticias-51754382

Banco Interamericano de Desarrollo. (2016). El porqué de la relación entre género y transporte. BID. https://publications.iadb.org/en/publications/spanish/document/ El-porqu $\% \mathrm{C} 3 \% \mathrm{~A} 9$-de-la-relaci\%C3\%B3n-entre-g\%C3\%A9nero-y-transporte.pdf

Boros, G. (2014). Exclusiva-Sondeo: El transporte público en ciudades de Latinoamericanas es el más peligroso para las mujeres. Thomson Reuters Foundation News. https://news. trust.org/item/20141028185437-g5lt6/

Corte Interamericana de Derechos Humanos. (2009). Caso González y otras ("Campo Algodonero") contra México. Excepción preliminar, Fondo, Reparaciones y Costas. Sentencia del 16 de noviembre de 2009. Serie C, Número 205. http://www.corteidh. or.cr/docs/casos/articulos/seriec_205_esp.doc

Diario Oficial de la Federación. (junio, 2018). Ley para la igualdad entre hombres y mujeres. Cámara de Diputados del Honorable Congreso de la Unión. http://www.diputados. gob.mx/LeyesBiblio/pdf/LGIMH_140618.pdf

Foucault, M. (2015, Cuarta reimpresión). Vigilar y castigar. México: Siglo XXI. 
Gómez, L. (8 de agosto, 2020). Avanza marcha feminista por Paseo de la Reforma. La Jornada, Capital. https://www.jornada.com.mx/ultimas/capital/2020/08/16/avanza-marcha-feminista-por-paseo-de-la-reforma-1217.html

Gobierno de la Ciudad de México. (noviembre, 2019). Se publica en Gaceta Oficial Declaratoria de Alerta por Violencia de Género. México: Jefatura de Gobierno. https://jefaturadegobierno.cdmx.gob.mx/comunicacion/nota/ se-publica-en-gaceta-oficial-declaratoria-de-alerta-por-violencia-de-genero

Hierro, G. (2002). Madres simbólicas del feminismo en México. En Feminismo en México. Revisión histórico-crítica del siglo que termina. México: Programa Universitario de Estudios de Género, Universidad Nacional Autónoma de México. https://cieg.unam. $\mathrm{mx} /$ docs/publicaciones/archivos/102.pdf

Hincapié, S. (2017). Acción colectiva de las mujeres y derechos humanos en México: movilizando el dolor en medio del conflicto armado. Estudios socio-jurídicos, 19(2), 97-127. Obtenido de: http://dx.doi.org/10.12804/revistas.urosario.edu.co/sociojuridicos/a.5255

Infobae. (octubre, 2020). La imagen que indigna a México: una policía tocando a una manifestante en la entrepierna. Obtenido de: https://www.infobae.com/america/ mexico/2020/10/01/la-imagen-que-indigna-a-mexico-una-policia-tocando-a-una-manifestante-en-la-entrepierna/

Instituto Nacional para el Federalismo y el Desarrollo Municipal. (2019). Conmemoramos 64 años del voto de la mujer en México. Secretaría de Gobernación. https://www.gob.mx/inafed/ articulos/64-aniversario-del-voto-de-la-mujer-en-una-eleccion-federal-en-mexico

Marco Normativo Comisión Nacional de Derechos Humanos. (2021). Ley general de acceso de las mujeres a una vida libre de violencia. https://www.cndh.org.mx/sites/ default/files/documentos/2019-04/Ley_GAMVLV.pdf

Secretaría de las mujeres. (2021). Campaña Viaja Segura. Gobierno de la Ciudad de México. https://www.semujeres.cdmx.gob.mx/vida-libre-de-violencia/viaja-segura

Secretariado Ejecutivo del Sistema Nacional de Seguridad Pública. (2020). Información sobre violencia contra las mujeres. Incidencia delictiva y llamadas al 9-1-1. Centro Nacional de Información. Secretaría de Seguridad y Protección Ciudadana. https:// drive.google.com/file/d/1IzlZK1O_yWfIz8FsNYzL_VcL69DJcAEX/view 